MUSEOLOGIA

\section{MUSEU \\ NACIONAL \\ CELEBRA 200 ANOS}

Quando Dom João VI assinou o decreto para a construção do $\mathrm{Mu}$ seu Real, em 6 de junho de 1818, o evento foi saudado como uma iniciativa para a elaboração de uma cultura científica em prol dos interesses coloniais: "Propagar os conhecimentos e estudos das ciências naturais no Reino do Brasil, que encerra em si milhares de objetos dignos de observação e exame e que podem ser empregados em benefício do comércio, da indústria e das artes", escreveu Dom João VI, sobre os motivos que o fizeram construir o Museu Real. Considerado o marco zero do processo de institucionalização da ciência brasileira, após a proclamação da República, em 1889, passou a se chamar Museu Nacional. "Na época da inauguração, o museu representava muito pouco para a sociedade brasileira. Era um depósito cheio de promessas. Ele só começou a ser influente e interessante algum tempo depois, a partir das primeiras exposiçōes públicas em 1821", explica Luiz Fernando Dias Duarte, diretor adjunto do Museu Nacional. Para Claudia Rodrigues Carvalho, do Departamento de Antropologia do Museu, ele teve um papel fundamental como precursor de pesquisas no Brasil, incentivando

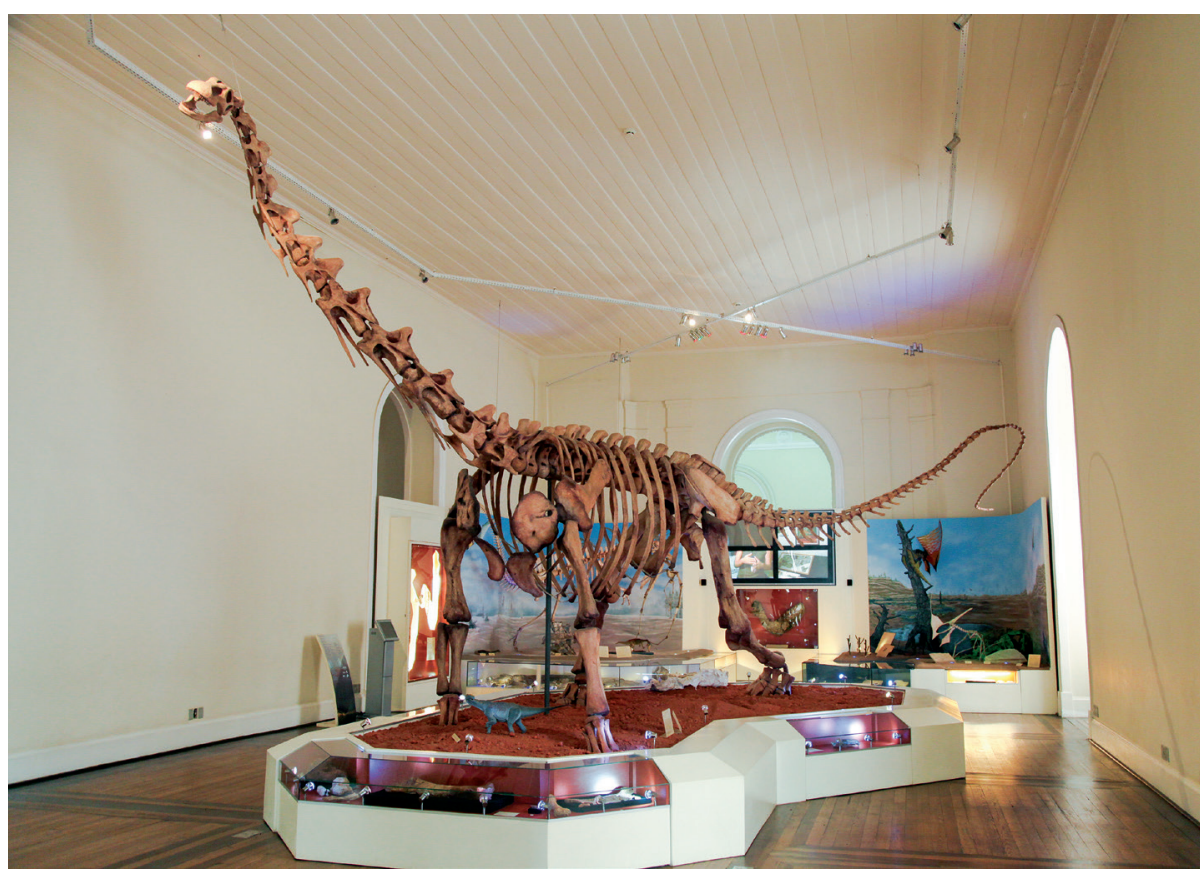

Crise orçamentária fez com que sala de exposição dos fósseis ficasse fechada à visitação

a criação de outras instituições nas mais diferentes áreas das ciências naturais e humanas. "O bicentenário do Museu Nacional representa muito mais do que o aniversário de uma instituição. Significa o início de uma política de estado voltada para a pesquisa, alicerçada em suas coleçōes. Antes do museu já se fazia ciência no país, mas sua criação reflete uma política de estado que se volta para a valorização da ciência enquanto produtora de conhecimento e estratégica para o crescimento do país", afirmou.

ACERVO ÚNICO O exuberante palácio de estilo neoclássico, sede do $\mathrm{Mu}$ seu Nacional, abriga um acervo com mais de vinte milhões de itens. Peças de diferentes áreas como antropologia, biologia, botânica, arqueologia, zoologia, etnologia, geologia e paleontologia impressionam as mais de 180 mil pessoas que visitam o museu todos os anos. Uma extensa coleção que já encantou cientistas como Albert Einstein, Marie Curie e Santos Dumont. "O que mais me impressionou foi a variedade", disse o administrador Nilson Cavalcante, pernambucano e residente no estado do Rio de Janeiro há mais de duas décadas. "Meteoritos, fósseis, arte egípcia, artefatos indígenas, documentos da época do império... tudo aqui é muito interessante". O Museu Nacional também ostenta o título de maior coleção de artigos da história egípcia da América do Sul. Estátuas, esquifes, hieróglifos e múmias vieram das coleçôes de Dom Pedro I e Dom Pedro II, admiradores da antiga cultura egípcia. A imperatriz Teresa Cristina, esposa de Dom Pedro II, foi outro membro da família real que contribuiu assiduamente com o acervo do museu. Simpati- 

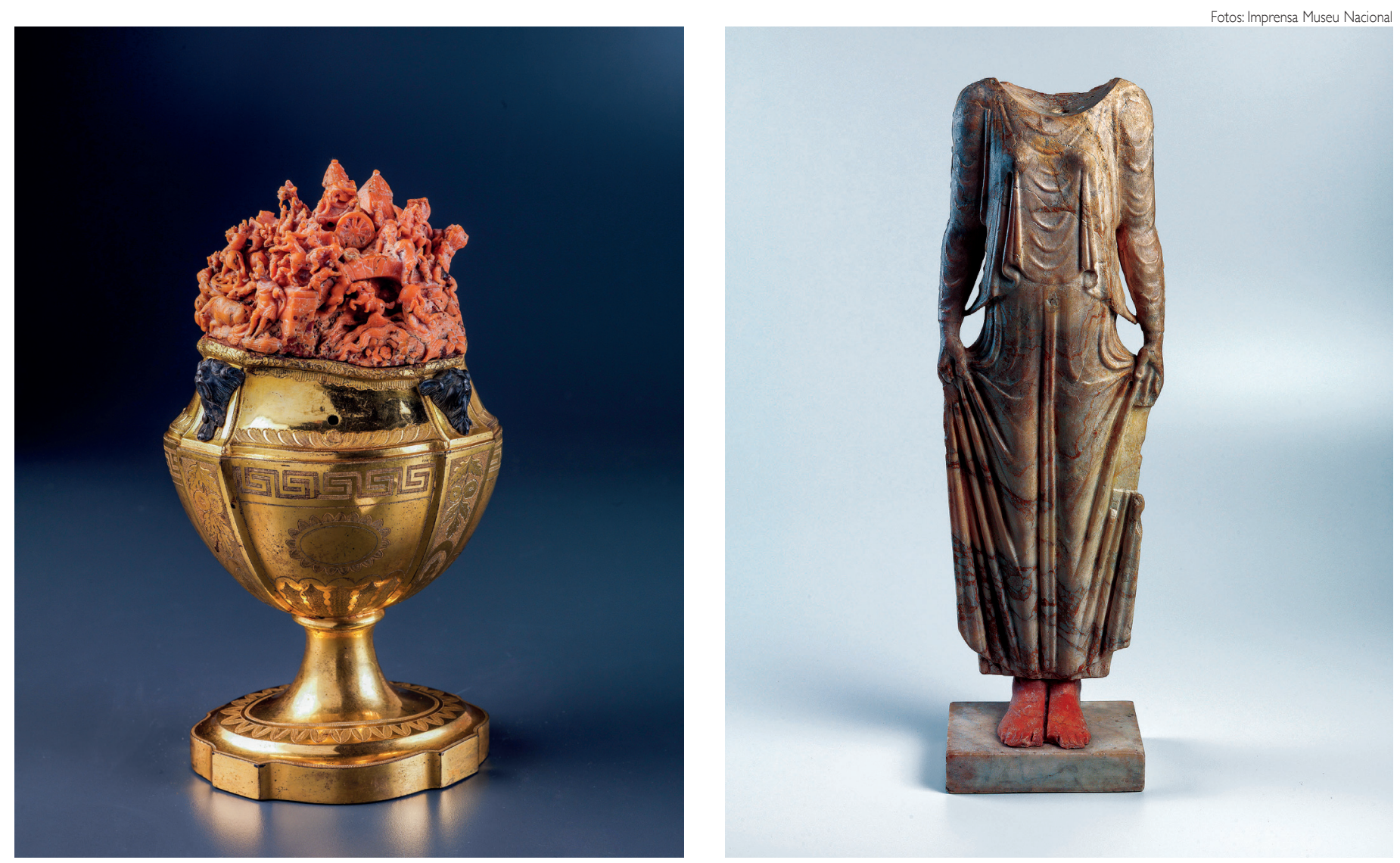

Taça-cofre "Batalha de Constantino" e escultura feminina sem cabeça, em mármore, peças doadas pela imperatriz Tereza Cristina

zante da ciência, ela patrocinou uma série de escavações arqueológicas na Itália. Parte das peças coletadas nessas expedições fazem parte da coleção greco-romana do museu. "Destaco a estatueta Koré (que representa uma figura feminina de pé), uma peça de estilo arcaico, provavelmente uma cópia romana, encontrada no sítio etrusco de Veio. Composta por dois tons de mármore, é uma peça rara que expressa grande elegância” destaca Duarte.

MOMENTO DELICADO No discurso de aniversário de 100 anos do Museu Nacional, Edgar Roquette-Pinto, um dos maiores cientistas brasileiros e um dos pioneiros da radiodifusão nacional, enfatizou que a sociedade e o poder público deveriam ter mais esmero para que a mensagem científica da instituição não fosse prejudicada. No segundo centenário a mensagem segue atual, dado os recentes cortes no orçamento para a ciência no Brasil, que também afetam o museu. Administrado pela Universidade Federal do Rio de Janeiro (UFRJ) desde a década de 1940, a instituição trabalha com um orçamento anual de R $\$ 520$ mil, valor que não permite, por exemplo, disponibilizar toda a coleção do museu para visitação. Em termos de comparação, o Museu Americano de História Natural, em Nova York, Estados Unidos, tem o orçamento anual de U\$ 657 milhões. Já o Museu de História Natural de Londres, no Reino Unido, recebe por ano $£ 80$ milhões para manter a coleção museológica. Apenas um por cento de todo o extenso acervo do Museu Nacional está exposto para os visitantes por conta, principalmente, de falta de espaço e de manutenção das câmaras expositivas. Um caso que ilustra a gravidade do problema é o que aconteceu recentemente na sala que abriga o fóssil do Maxakalisaurus topai, dinossauro brasileiro mais antigo já descoberto. O local, um dos mais populares entre os visitantes, está fechado devido a um ataque de cupins que ruiu sua estrutura. Uma vaquinha virtual organizada 
pela direção do museu conseguiu arrecadar cerca de 50 mil reais para a revitalização e reabertura dessa sala. No entanto, a instituição tem problemas que vão além de sua estrutura física, como as ameaças de quebra de contrato com empresas que prestam serviços terceirizados. "A situação em que o Museu Nacional e toda a UFRJ

\section{NA ACADEMIA}

\section{E NA SOCIEDADE}

Hoje, o Museu Nacional é um importante centro de estudos multidisciplinares que reúne pesquisadores de toda a América Latina. A instituição é responsável por cursos de extensão acadêmica e pós-graduação em diferentes áreas de conhecimento, inclusive com a primeira experiência brasileira de um mestrado em línguas indígenas. "Já temos seis cursos de pós-graduação, sendo um de nível 7, de antropologia, e outro de nível 6, de zoologia, na classificação da Capes", informa Duarte. Com 330 espécies de vegetais de todas as regiões do país, o horto botânico é um importante laboratório para pesquisadores e um chamariz para crianças e adolescentes visitarem o museu, por meio do projeto "Escola na trilha", realizado desde 2011. se encontram é patética. Volta e meia, somos ameaçados de perder os contratos de serviços básicos como limpeza e vigilância, o que já motivou alertas e até fechamentos de exposições nos últimos anos. Neste momento, por exemplo, a ruptura do contrato de jardinagem está afetando o horto botânico", conta Duarte. Segundo ele, o orçamento apertado também atrapalha a atividade acadêmica. "A contenção dos recursos das agências financiadoras, como o Conselho Nacional de Desenvolvimento Científico e Tecnológico (CNPq), ameaça a publicação de uma de nossas melhores revistas, a Mana: estudos de antropologia social. Não temos recursos para publicar o terceiro número deste ano", lamenta o diretor adjunto. Os problemas estruturais são perceptíveis para os visitantes e turistas. A bela fachada do palácio imperial não esconde as infiltraçôes, há fios elétricos expostos e paredes com mofo no prédio histórico. "Um lugar como esse deveria ser bem mais cuidado. Acho que o museu representa bem o atual momento do Rio de Janeiro. Rico em cultura, mas abandonado pelo poder público", lamenta a microempresária Maiara Almeida, em visita ao museu. Em entrevista para o jornal Folha de S.Paulo, do último dia 30 de maio, Alexander Kelnner, diretor do museu, revelou que seriam necessários investimentos de $\mathrm{R} \$ 300$ milhões, ao longo de 10 anos, para que a instituição alcançasse o nível dos melhores museus do mundo.

Allison Almeida

\section{RESENHA}

\section{DiÁlOGO} CONTROVERSO E ATUAL SOBRE O

Existe uma lógica do conhecimento, da invenção, da descoberta científica? É em torno de tão controverso tema, o da teoria do conhecimento, que o educador Anísio Teixeira e o médico Maurício Rocha e Silva travaram um elegante e duro embate por meio de correspondência trocada entre dezembro de 1965 e abril de 1967. A batalha apaixonada de conceitos e posições contrárias dos pensadores acerca dos processos (lógicos ou nada lógicos) que levam à construção do conhecimento científico aconteceu em pleno regime militar brasileiro e seus atos institucionais. As cartas foram organizadas em livro, editado primeiramente em 1968, e republicado em 2007, pela editora da Universidade Federal do Rio de Janeiro (UFRJ), quase 40 anos depois. E, mesmo após tanto tempo, é possível identificar ali a contemporaneidade da discussão que ainda hoje divide a ideia do conhecimento entre ciências humanas e exatas, arte e ciência, e que funciona como obstáculo à produção e ao acesso a novos conhecimentos científicos.

Curiosamente intitulado Diálogo sobre a lógica do pensamento, o que menos se percebe ao longo das 121 páginas é uma conversa entre os dois pensadores. O exercício da dialética, que parte do reconhecimento da posição adversa, não acontece 